\title{
Análise do Processo Decisório para Seleção de Rodovias a Serem Pedagiadas no Brasil
}

\author{
João Gualberto Coutinho Rocha \\ Rosângela Maria Vanalle
}

\section{Resumo}

O presente artigo procura apresentar o processo de decisão para seleção das rodovias integrantes da malha viária brasileira, que estão sendo submetidas ao regime de concessão à iniciativa privada, por meio de sua exploração pela cobrança de pedágio. A análise do processo mostra que o instrumento básico para seleção dos trechos considerados viáveis tem sido a avaliação dos empreendimentos sob o enfoque de project financing, cujo indicador de viabilidade é o grau de cobertura do serviço da dívida a ser contraída para realização dos investimentos programados. Na medida em que o project financing é um instrumento parcial de indicação de viabilidade e prioridade econômica, o artigo, no final, propõe um modelo mais abrangente para as tomadas futuras de decisão, em especial porque o programa nacional de concessões de rodovias está ainda em boa parte por se realizar.

Palavras-chaves: concessão de rodovias; processos decisórios; análise de projetos; financiamento a projetos.

\section{Abstract}

The present article intends to discuss the process of decision involving the Brazilian highways concession program, that is submitting to the private administration under toll system the most important Brazilian highways. The analysis proceeded indicates that the basic decision instrument used in this process is the project financing model, which concedes priority to the projects that are able to guarantee the return of the investments made in accordance to its cash flow. As the project financing model focus only in the financial aspects of the projects, this article tries to formulate, at the end of the text, an alternative proposal to the actual Brazilian process of decision, submitting it to a wider criteria, specially because the program has more than $50 \%$ to be executed in the next years.

Key words: highways concession; decision process; project evaluation; project financing. 


\section{INTRODUÇÃO}

Tem-se observado, ao longo dos últimos anos, um processo crescente de transformação nas relações e atribuições entre o poder público e a iniciativa privada, tanto no Brasil como em diversos outros países do mundo. Após um período marcado pela transferência do controle de empresas até então estatais para o setor privado, mais recentemente a administração pública brasileira tem empreendido amplo programa de concessão de serviços de utilidade pública, em especial nos segmentos de infra-estrutura: energia, transportes, telecomunicações etc. (Pinheiro e Fukasaku, 2000).

Entre os segmentos da infra-estrutura pública recentemente concessionados à iniciativa privada, destaca-se a malha rodoviária brasileira, cuja adoção do sistema de pedágio como forma de viabilizar a participação da iniciativa privada, além de provocar diversos debates e polêmicas (Porto, 1999; Pimentel Neto, 2000), certamente promove custos e benefícios ao longo de toda a cadeia produtiva que dessa infra-estrutura se utiliza.

O processo decisório adotado para selecionar os trechos rodoviários passíveis de submissão ao sistema de pedágio, portanto passíveis de concessão à iniciativa privada, torna-se, neste contexto, fundamental à administração pública, no sentido de garantir a maximização dos benefícios líquidos a serem agregados à economia nacional, em especial se for considerada a dimensão do programa de concessão de rodovias brasileiras ora em curso.

\section{O Programa Nacional de Concessão de Rodovias}

Até 1997, o segmento de rodovias no Brasil era integralmente gerido pelo Poder Público, tanto na esfera federal, como nas esferas estaduais e municipais. Tal gestão abrangia as tarefas de planejamento, manutenção, investimentos, operação e, em poucos casos, a administração de praças de pedágio.

A partir de 1998 as rodovias brasileiras vêm sendo submetidas a um amplo programa de parceria entre o setor público e a iniciativa privada (Cherobim, 1999), resultando na concessão de quase $10.000 \mathrm{~km}$ de rodovias ao setor privado, o qual conta com 37 concessionárias (BNDES, 2000), sendo prevista, ainda, a concessão de mais 12.000 km da malha rodoviária nacional nos próximos anos, consideradas as concessões federais, estaduais e municipais, conforme tabela a seguir. 


\section{Tabela 1: Programa de Concessões de Rodovias no Brasil}

\begin{tabular}{|l|r|r|r|}
\hline \multirow{2}{*}{$\begin{array}{c}\text { Programa de Concessão } \\
\text { de Rodovias }\end{array}$} & \multicolumn{3}{|c|}{ Extensões $(\mathrm{km})$} \\
\cline { 2 - 4 } & Realizado & A realizar & Total \\
\hline Programa Federal & 856,4 & $7.084,1$ & $7.940,5$ \\
Programa São Paulo & $3.517,0$ & $2.710,0$ & $6.227,0$ \\
Outros Estados e Municípios & $5.572,0$ & $2.623,0$ & $8.195,0$ \\
\hline \multicolumn{1}{|c|}{ Total } & $9.945,4$ & $12.417,1$ & $22.362,5$ \\
\hline
\end{tabular}

Fonte: DNER (1998a), BNDES (2000).

De acordo com a tabela acima, o fenômeno das concessões rodoviárias, no Brasil, atinge as esferas federal, estadual e municipal (DNER, 1998; BNDES, 2000).

No nível federal, cinco trechos rodoviários foram concedidos à iniciativa privada: ponte Rio-Niterói, rodovia Presidente Dutra, BR-040 trecho Rio de Janeiro/Juiz de Fora, BR116 trecho Rio/Teresópolis/Além Paraíba e rodovia Porto Alegre/Osório; outros 7 trechos estão atualmente em fase de licitação (DNER, 1999).

Nas esferas estaduais, os Estados de São Paulo, Paraná, Rio de Janeiro, Minas Gerais, Santa Catarina, Bahia e Espírito Santo já empreenderam experiências e efetivaram concessões.

Finalmente, também na esfera municipal, já existe experiência no mesmo sentido: caso da implantação da Linha Amarela, no município do Rio de Janeiro.

O que ocorre no Brasil deriva, em parte, da experiência cumprida em outros países, conforme destaca Oliveira (2001), incluindo nações européias, como França, Espanha e Portugal, entre outras, e latino-americanas, em especial Argentina e México, a partir das quais o programa brasileiro foi pautado.

Todos os projetos empreendidos sob o regime de concessão, no caso rodoviário brasileiro, têm-se valido de um planejamento de investimentos e financiamento baseado no modelo project financing, como forma de selecionar os programas de investimento viáveis e passíveis de serem submetidos ao interesse privado, qualquer que tenha sido a esfera da administração que o tenha implementando: federal, estadual ou municipal.

\section{O Modelo Project financing}

Project Financing é um modelo de financiamento de projetos de investimentos, 
cuja avaliação de viabilidade e hierarquização de prioridades leva em conta a capacidade do projeto de gerar recursos diretos para recuperação dos capitais investidos.

Em outras palavras, Project Financing é uma expressão que, talvez por não encontrar tradução adequada para a língua portuguesa, se consagrou no meio bancário e empresarial como a metodologia segundo a qual se analisa um projeto de investimento em que a capacidade de geração de retorno e a oferta de garantias se vinculam exclusivamente ao seu fluxo de caixa, não se considerando nenhum estoque patrimonial ou fluxo de recursos dos empreendedores.

Borges (1998) define project financing como sendo uma forma de engenharia financeira, sustentada contratualmente pelo fluxo de caixa do projeto, servindo como garantia aos financiamentos tomados, exclusivamente os valores recebíveis ao longo do período de vida econômica do projeto.

Apesar de sua aplicabilidade ser teoricamente possível para todo o tipo de projetos, o project financing tornou-se instrumento amplo e especificamente mais utilizado no financiamento de projetos nos setores de infra-estrutura, como usinas elétricas, rodovias, saneamento básico, extração de petróleo, entre outros (Borges, 1998).

Neste sentido, Ferreira (1996) destaca que a viabilidade de projetos de infraestrutura, construídos e operados pelo setor privado, exige a utilização da modelagem de financiamento definida como project financing, em que se incorpora uma mudança no perfil de risco do projeto, pois um projeto de investimento em infra-estrutura, sob gestão da iniciativa privada, forçosamente restringe seu risco sobre o desempenho do projeto, já que os ativos construídos (rodovias, portos etc.) são bens públicos e os empreendedores privados não se dispõem a oferecer garantias reais ou a onerar sua capacidade de crédito, ao envolverem-se em projetos de infra-estrutura de uso e propriedade públicos.

Project financing, portanto, é um modelo de financiamento de projetos, cujos critérios de análise de viabilidade econômica se baseiam na capacidade do projeto de oferecer garantias de retorno em nível suficiente e adequado para proporcionar a recuperação dos investimentos realizados, sejam estes com recursos próprios dos empreendedores, sejam especialmente com recursos de agentes financiadores (Rocha e Vanalle, 1999).

O seu uso também introduz importante variável de competitividade entre agentes interessados em desenvolver determinado projeto, pois aqueles mais bem capacitados em montar uma competente engenharia financeira, gozarão de melhores condições para a gestão do projeto e, no caso de este ser um projeto de infra-estrutura pública, gozarão de melhores condições de competição em processo licitatório. 
No caso das rodovias, por se tratar de projetos de infra-estrutura de uso público, o envolvimento da iniciativa privada se formaliza mediante licitação, em que os agentes interessados apresentam suas propostas de acordo com as regras previamente estabelecidas pelo poder concedente (administração pública). No caso brasileiro, apesar de tais processos se diferenciarem quando implementados pela administração pública federal ou por outra esfera governamental, a modelagem project financing está sempre presente, de forma direta ou indireta, no processo decisório, tanto para seleção das rodovias a serem oferecidas à iniciativa privada, como para seleção dos agentes privados licitantes (Rocha, 2001).

\section{O Processo de Decisão para Seleção de Rodovias a Licitar}

No caso brasileiro, e no caso específico do processo de concessões de rodovias, tomando por base os documentos oficiais do poder concedente (governo federal por meio do DNER e governos estaduais), pode-se compreender a estruturação do planejamento de programas e projetos segundo o apresentado na Figura 1, a seguir.

\section{Figura 1: Fluxograma Geral do Processo de Decisão acerca do Programa de Concessões Rodoviárias no Brasil}

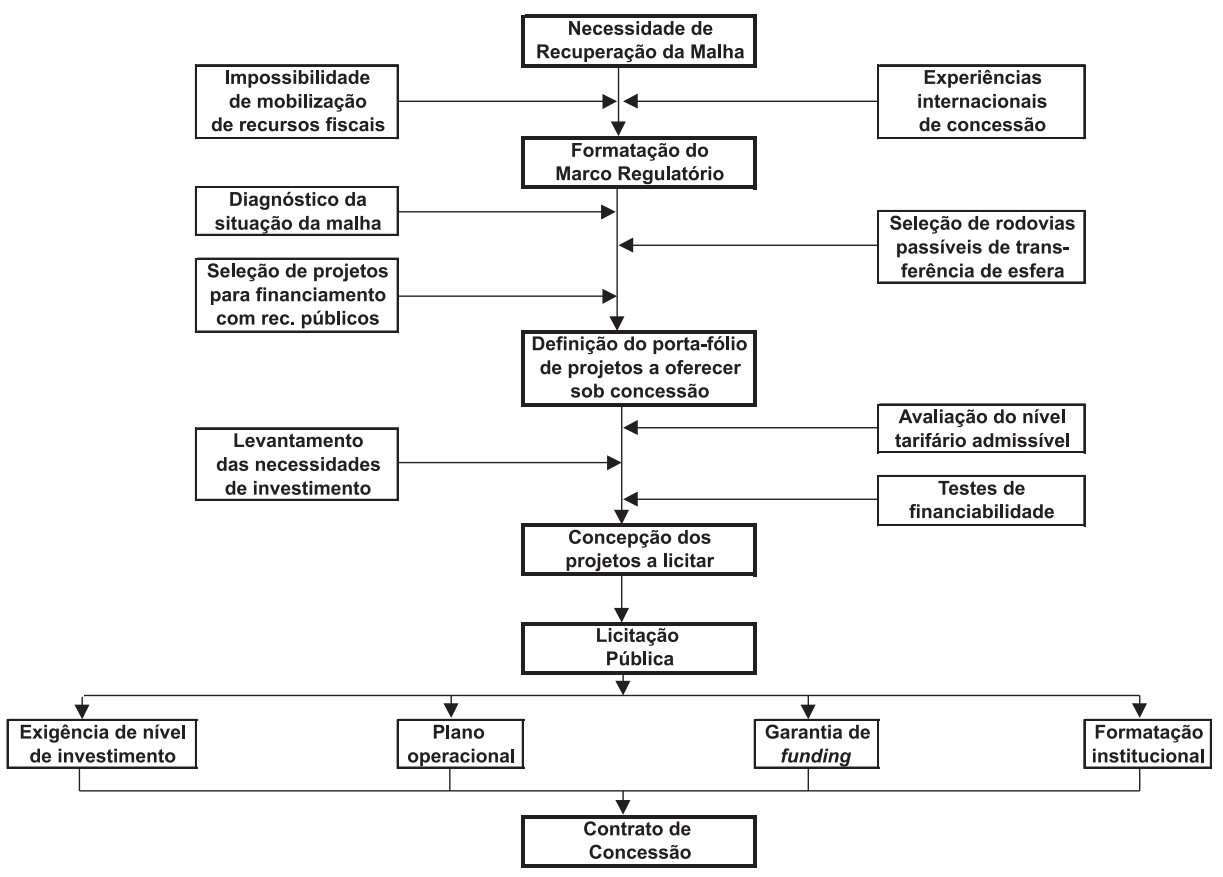


O processo de decisão quanto à concepção e seleção de projetos a implementar no segmento rodoviário brasileiro sob o regime de concessão, pode efetivamente ser compreendido, a partir da necessidade de recuperação da malha e da incapacidade de mobilização de recursos públicos para tal.

Este entendimento pode ser caracterizado pela apresentação do Programa de Concessões de Rodovias Federais, pelo DNER (1998a, p. 3), onde se afirma que "essa situação se explica pela falência do modelo de financiamento [...] que se apoiava na vinculação dos recursos [...] Para corrigir o desequilíbrio entre os recursos disponíveis e suas responsabilidades [...] o governo federal vem tendendo, progressivamente, a [...] transferir responsabilidades por novos investimentos [...] para as concessionárias privadas”.

A motivação primeira, portanto, do governo federal vincula-se ao desequilíbrio entre disponibilidade de recursos de origem fiscal e demanda por investimentos em manutenção e/ou melhorias da malha rodoviária.

Tal motivação não é diferente nas esferas estaduais, onde em São Paulo, por exemplo, o governo, na apresentação do Programa Estadual de Desestatização e Parcerias com a Iniciativa Privada (São Paulo, Governo do Estado, Secretaria dos Transportes, 1995, p.3), afirma que "a participação da iniciativa privada na prestação de serviços públicos é a mais importante alternativa para viabilizar investimentos em infra-estrutura”.

Determinada a necessidade de implementação do programa e o caminho a seguir, via iniciativa privada, a formatação do marco regulatório para sua implementação se fez necessária, o que acabou por ficar baseado na lei federal 8.987/95 e legislação complementar. E uma vez já se dispondo do marco regulatório, o processo, no Brasil, cumpre a seguir a etapa de definição do porta-fólio de projetos a se avaliar para efeitos de concessão.

Esta análise se dá sobre aspectos associados ao volume de investimento demandado por cada trecho rodoviário, por seu papel estratégico dentro do sistema de transporte e pelas expectativas preliminares de atratividade econômica da rodovia perante a iniciativa privada. Tal afirmação está consubstanciada na lista de ações empreendidas pelo governo federal, a partir de 1993, conforme enunciado em DNER (1998a), em que em paralelo à recuperação de trechos críticos e à execução de outras obras pelo poder público federal, se transferiram rodovias para os governos estaduais, para que estes as concedessem à iniciativa privada ou as administrassem diretamente, e iniciou-se o programa federal de concessões.

A transposição do estágio de definição do porta-fólio de projetos a oferecer sob 
o regime de concessão e a concepção dos projetos a licitar têm promovido três ações básicas: o levantamento das necessidades de investimento, a avaliação do nível tarifário admissível e testes de financiabilidade. Após definidos tais aspectos é que os projetos financiáveis são licitados.

Na fase de licitação, conforme se pode observar nos editais lançados por governos estaduais e pelo governo federal (São Paulo, 1998b; DNER, 1998b), é que são definidos o nível de investimento a se realizar (fruto dos levantamentos de necessidade e dos testes de financiabilidade), o plano de operação (em parte, associado ao nível tarifário admissível), as exigências quanto à capacidade de mobilização dos recursos (função da financiabilidade exigida) e o formato institucional da concessionária (este, um ponto vinculado ao marco regulatório do programa).

A seqüência do processo decisório adotado no Brasil caracteriza-se por um planejamento de investimento em que os projetos são analisados e, a partir daí, selecionados, em função do padrão de financiamento que são capazes de absorver; portanto o processo decisório vincula-se exclusivamente ao modelo project financing.

Isto fica caracterizado pelo própria motivação do programa (impossibilidade de manutenção do modelo de financiamento até então vigente com uso de recursos públicos); pelo processo de definição do porta-fólio de projetos a oferecer sob concessão (aqueles não passíveis de financiamento público ou não transferíveis a outras esferas de governo); e, principalmente, na concepção dos projetos a licitar, os quais são planejados em função de um equilíbrio entre as necessidades de investimento, o nível tarifário e sua financiabilidade.

Todos estes pontos confirmam que o processo decisório acerca da seleção dos projetos a licitar, sob o regime de concessão, utilizam como instrumento central os indicadores produzidos pelo método project financing. E o processo licitatório para seleção do agente privado a ser constituído como titular da concessão ofertada, derivando do processo de formulação do programa, mantém a tendência de vincular-se exclusivamente a um padrão de project financing.

\section{O Processo Decisório Inserido nas Licitações de Rodovias a Conceder}

A base institucional dos processos de envolvimento da iniciativa privada em programas de concessão de serviços e infra-estrutura públicas, requer seqüência lógica no processo decisório em todas as suas etapas, desde a tomada de decisão 
do poder público de implementar o programa de concessão, até o processo de seleção dos agentes privados para formalização da parceria, pela licitação.

Assim, o processo de seleção do agente privado, neste contexto, apresenta-se justaposto ao de decisão quanto à implementação do projeto de concessão, sendo o processo licitatório que lhe dá causa um reflexo das decisões e modelos anteriores que permitiram a própria efetivação da licitação.

Por se tratar de um serviço público precedido por obra pública, a seleção dos agentes privados, em todos os países, se dá por meio de um processo licitatório, em que a legislação pertinente regula a matéria caso a caso (Wald, Moraes e Wald, 1996).

De modo geral, o objetivo de um processo licitatório é o de selecionar a proposta mais vantajosa para o poder público e para a sociedade, garantindo-se ainda o direito a todos os interessados capacitados em apresentar sua proposição.

Pautados teoricamente nestas intenções e sentido, cada agente público no Brasil tem promovido os processos licitatórios, para concessão de rodovias, sob critérios distintos para seleção dos agentes privados, conforme exemplificado a seguir.

. No programa de concessão de rodovias federais, a variável de decisão adotada é a menor tarifa básica de pedágio oferecida pelos diferentes candidatos a concessionário (DNER, 1998b).

. No programa do anel de integração rodoviária do Paraná, a variável de decisão adotada foi a maior oferta (em quilômetros) de trechos rodoviários adicionais a serem conservados (ABCR, 1998).

. No programa de concessões rodoviárias de São Paulo, a vitória nas licitações levadas a efeito baseou-se na maior oferta de pagamento de ônus fixo pela outorga da concessão (São Paulo, Governo do Estado, Secretaria dos Transportes, 1998a).

. Na concessão do complexo rodoviário Estrada do Coco - Linha Verde, na Bahia, a licitação foi vencida pela proponente que demandou menor aporte de recursos públicos no empreendimento (UNITEC, 1999).

Assim, fica caracterizado que, independentemente do fator de decisão adotado no seio da licitação, em última análise, o modelo está pautado no padrão project financing, pois a oferta de menor tarifa, maior quilometragem a ser conservada, maior ônus fixo ou menor aporte de recursos públicos só pode ser decidida mediante a análise do fluxo de caixa do empreendimento, em que se assegure previa- 
mente capacidade de retorno aos financiamentos a serem tomados (portanto sob o modelo project financing).

Tal processo decisório acerca de investimentos em rodovias, tanto na etapa de formulação do conjunto de rodovias a licitar como na seleção dos agentes privados, diferencia-se do processo adotado no passado, quando as rodovias eram exclusivamente geridas pelo Poder Público, pois os métodos de análise dos investimentos a realizar baseavam-se nas metodologias de Benefícios menos Custos ou de Análise Multicritérios, ambas interessadas em estabelecer prioridades de investimento com base no maior retorno econômico, ao invés de simplesmente no seu retorno financeiro (Rocha, 2001).

\section{Os Métodos tradicionais de Análise de Projetos RodoviáRIOS}

A característica principal de um projeto de investimento em infra-estrutura rodoviária é que o seu retorno econômico transcende as fronteiras da rodovia, atingindo outros setores econômicos, usuários diretos ou não, da malha rodoviária (Rigolon e Piccinini, 1997).

Um projeto de rodovia, por outro lado, proporciona retorno centrado na redução dos custos de transportes e dos benefícios pela redução do tempo das viagens e pela redução de acidentes e promove estímulo à atividade econômica em sua área de influência. Tal conjunto de benefícios não é passível de monetização direta, exigindo obrigatoriamente tratamento econômico (e não apenas financeiro) para efeito da avaliação de sua viabilidade.

Tal característica fez com que o setor de transportes e, muito especialmente, o segmento de infra-estrutura rodoviária, tivessem seus projetos, ao longo das últimas décadas, submetidos necessariamente a análises capazes de captar custos e benefícios em sua dimensão econômica.

\section{Análise pelo Método Benefícios Menos Custos}

A metodologia de avaliação conhecida como Benefício Menos Custos (ou, simplificadamente, método B-C), largamente utilizada desde os anos 60, consiste basicamente na determinação dos custos e benefícios promovidos pelo projeto sobre sua área de influência, no seu lançamento em um fluxo econômico e na comparação de seus indicadores de viabilidade (taxa interna de retorno - TIR e/ ou valor presente líquido) com o de outros projetos ou com indicadores previamente adotados como aceitáveis. 
A determinação de custos e benefícios nos projetos de transporte, segundo Adler (1978) ou Bruton (1979), deriva dos estudos de tráfego, nos quais se avalia o tráfego existente, sua projeção, a geração de novos fluxos a partir da implantação do projeto e sua distribuição sobre a malha de transporte. Conhecido o tráfego do projeto, estudam-se os custos e os benefícios a serem incorridos nas hipóteses com sua implantação ou sem ela.

Nesta metodologia os custos de transporte limitam-se, fundamentalmente, aos montantes de investimento com a realização do projeto (obras, novas instalações etc.) somados aos custos operacionais e aos de manutenção.

Quanto aos benefícios, Adler (1978) e BIRD, BNDES e DNER (1983) sugerem uma análise ampliada de efeitos, sempre sob a ótica comparativa entre os cenários com o projeto ou sem ele:

. redução do custo de transporte;

. redução dos custos de conservação e manutenção;

. redução de acidentes;

. redução dos tempos de viagem;

- aumento da produção na área de influência do projeto.

Os dois primeiros podem ser considerados como benefícios diretos, quer por estarem associados diretamente à rodovia e seu tráfego, quer pela possibilidade de sua mensuração monetária se dar também de forma direta, enquanto os benefícios por redução de acidentes, por redução dos tempos de viagem ou por aumento da produção podem ser entendidos como benefícios externos à rodovia (ou externalidades), uma vez que o agente que os aufere é exógeno à operação da rodovia propriamente dita.

Dimensionados custos e benefícios, seus valores marginais são lançados em um fluxo de caixa econômico, em que o investimento com o novo projeto aparece com sinal negativo (saída de caixa) e os benefícios (redução de custos, geração de incremento de produção etc.) recebem sinal positivo, como se fossem ingressos de caixa.

Dessa forma, o método B-C incorpora a análise de custos e benefícios que ultrapassam o simples balanço de efeitos diretos dos projetos de transporte, incorporando externalidades, ou seja, avaliando seus resultantes sobre a economia e a sociedade. 
Em resumo, portanto, o método B-C de análise de projetos de transporte procura dimensionar e comparar custos e benefícios econômicos promovidos pelo projeto, valendo-se para tanto de cenários com e sem o projeto, encaminhando as decisões de forma favorável ao reconhecimento da viabilidade dos projetos, sempre que estes forem promotores de benefícios líquidos (B-C > 0), priorizandoos em função de sua maior relação B/C ou pela maior geração de benefício por unidade de custo.

\section{Análise por Multicritérios}

A concepção básica do método de análise por multicritérios consiste na comparação qualitativa e/ou quantitativa de parâmetros do projeto em análise com o perfil do projeto desejado, definido como aquele de melhor geração de benefícios, conforme previamente traçado em um plano estratégico macroeconômico, normalmente concebido por órgãos públicos e/ou agências de desenvolvimento.

A operacionalização do método se dá por meio de uma matriz de avaliação por multicritérios, na qual são estabelecidos parâmetros obrigatórios e parâmetros desejáveis a serem cumpridos pelos projetos. Os parâmetros obrigatórios definem a viabilidade dos projetos analisados, enquanto os parâmetros desejáveis definem o seu grau de prioridade: quanto mais parâmetros são atendidos, maior prioridade possui o projeto.

Tal estrutura de análise, incorporando diferentes parâmetros, tanto de natureza quantitativa quanto qualitativa, traz consigo a dificuldade de ponderação entre os diferentes critérios para a tomada de decisão acerca de um determinado projeto e não deixa, em princípio, clara a questão da ordenação de prioridade entre projetos alternativos, dado o volume escasso ou limitado de recursos.

Várias alternativas para superar tais aspectos da metodologia são formuladas por diferentes autores, como Casarotto Filho e Kopittke (1998) e Clemente e Leite (1998); entretanto o que é relevante em sua adoção é o caráter abrangente dos elementos considerados no processo de decisão.

\section{O Uso das Metodologias de Análise de Projetos no Processo de Concessão de Rodovias}

Como já mencionado anteriormente, a seqüência do processo decisório adotado no Brasil para concessão de rodovias, caracteriza-se por um planejamento de investimento em que os projetos são avaliados e selecionados em função da estrutura de financiamento a que são susceptíveis de se submeter. 
Isto fica caracterizado pelo conteúdo dos documentos formais de planejamento do programa no nível federal. O processo decisório está explicitamente configurado em DNER (1998a, p.12), quando, ao descrever o processo de seleção de projetos a licitar para concessão privada, se afirma:

. “A análise financeira sob o ponto de vista privado confrontou as receitas esperadas da concessão [...] com os desembolsos inerentes aos investimentos e despesas".

. "A inviabilidade sob o ponto de vista privado determinou a exclusão de alguns trechos do programa".

- "Foram constatados alguns indicadores de viabilidade muito elevados em trechos simulados apenas para restauração. Nesses casos, foi analisada a viabilidade de intervenções mais arrojadas”.

. "Procedeu-se ainda à avaliação econômica social dos projetos [...] selecionados na análise privada (a avaliação social confronta os benefícios dos usuários [...] e suas despesas com o pagamento do pedágio) [...] essa análise permitiu também fixar o valor-limite admissível para a cobrança do pedágio”.

Dentro deste processo, observa-se praticamente o uso de apenas duas metodologias de análise e decisão: o project financing, que orienta quase todo o processo decisório, e um teste de admissibilidade do nível tarifário do pedágio, ou teste sob a ótica dos transportadores, que o DNER equivocadamente denomina "avaliação econômica social”.

Especialmente, portanto, quanto ao uso de metodologias de análise e decisão, a Figura 2, apresentada a seguir, demonstra a preponderância do modelo project financing nos programas brasileiros de concessão rodoviária.

Neste contexto, é possível perceber que o que se busca é, com um nível tarifário suportável pelo transportadores, maximizar os investimentos (e/ou custos operacionais) até o limite de viabilidade sob o critério project financing. Releva, portanto, enfatizar que o modelo acaba por privilegiar, por vezes, a maximização dos investimentos, ao invés de sua otimização, o que deveria ser perseguido em programa de eficiência alocativa.

Arbitrariamente, dentro de limites definidos de forma razoável, manipula-se nível tarifário e nível de investimentos e custos operacionais, até que o projeto passe por teste de financiabilidade e também sob a ótica dos transportadores. Se isto acontece, o projeto está pronto para ser licitado. Caso não se construa tal conjunto de viabilidade, o projeto é descartado em termos de concessão. 
Figura 2: Detalhamento do Uso das Metodologias de Análise de Projetos no Caso das Concessões Rodoviárias no Brasil

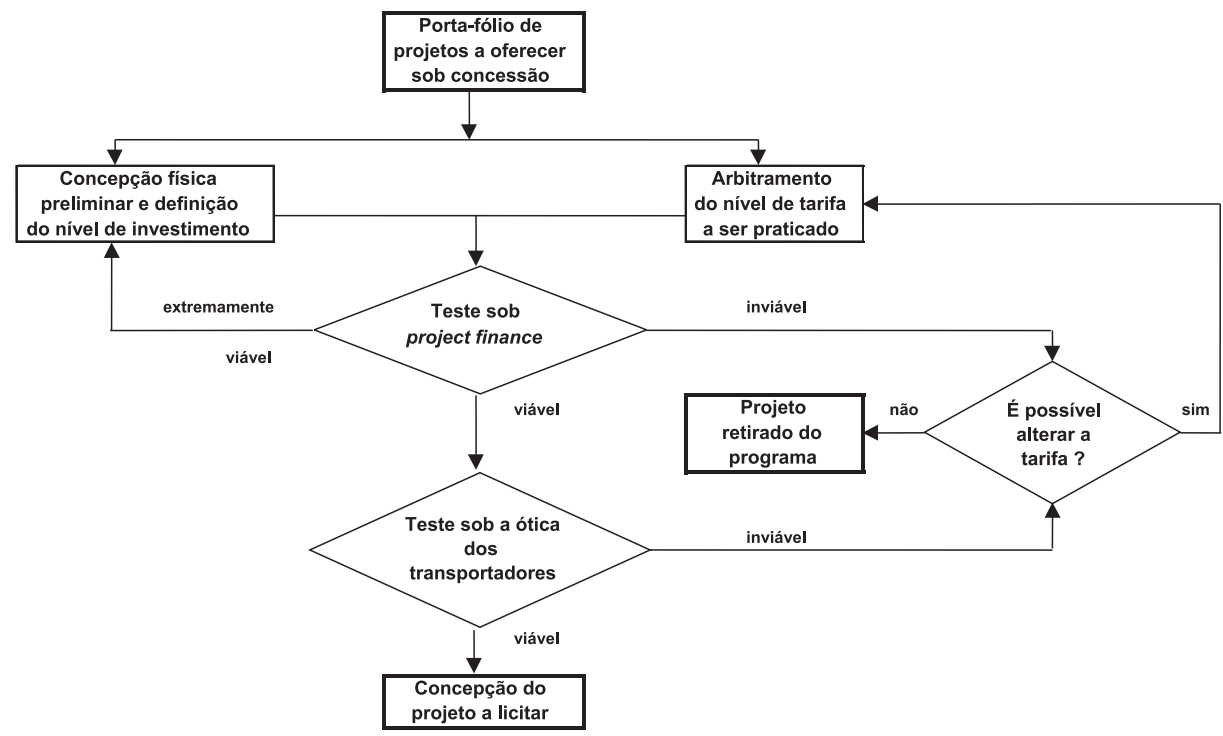

Este modelo, aqui construído a partir da prática observada e explicitamente adotada pelos órgãos nacionais competentes, em nenhum momento incorpora em seu processo de decisão o uso do modelo B-C ou de análise multicritérios.

Além disso, a concepção dos projetos é admitida como passível de revisão, caso seus primeiros desenhos, mesmo que eventualmente ótimos na abordagem B-C, se mostrem inadequados para financiamento privado.

Deflagrado pela necessidade de uma nova fonte de financiamento para o setor, o programa de concessões rodoviários no Brasil tem-se baseado, portanto, exclusivamente na busca de factibilidade para ingresso do capital privado, ajustando, para tanto, as próprias decisões quanto à concepção dos projetos, deixando apenas como conseqüência natural, a conquista de benefícios econômicos de caráter mais amplo, quando o inverso, via de regra, foi a prática no passado, quando a motivação pela realização de investimentos promotores de desenvolvimento econômico é que deflagrava o processo e definia os projetos prioritários a realizar para, só a partir daí, procurarem-se as melhores equações para seu financiamento.

A busca da eficácia, por certo, possui méritos em cenário reconhecidamente carente de realização de investimento. Por outro lado, é possível imaginar mecanismos e procedimentos decisórios que, mesmo sem abrir mão da eficácia, privi- 
legiem a eficiência alocativa de recursos escassos no estratégico segmento de infra-estrutura rodoviária.

\section{Aspectos a Considerar para Formatação de um Processo EFICIENTE}

Além da eficácia, ou seja, além de garantir a realização do programa de investimentos demandados, buscando a maximização dos projetos a realizar, um modelo de decisão para seleção de projetos deve ser eficiente em seu processo alocativo, procurando assegurar a realização do melhor conjunto de projetos, com o uso mais produtivo dos recursos a serem alocados em termos de retorno econômico para a sociedade; em especial se está se trabalhando sobre seleção de investimentos em equipamentos de uso público, promotores de relevante retorno macroeconômico.

Assim, a concepção de um modelo eficiente de decisão para alocação de recursos e seleção de projetos de investimento de infra-estrutura rodoviária deve ter em conta o seguinte:

. os projetos, independentemente de sua estrutura de financiamento, devem cumprir objetivos de caráter estratégico, pois o processo decisório sobre equipamentos de uso público deve obedecer, em primeira instância, a um vetor de política econômica e social, portanto estratégico;

- estrategicamente selecionado sob a ótica de política econômica, o projeto deverá apresentar uma avaliação de benefícios e custos econômicos positiva, ou seja, seus benefícios gerados deverão superar os custos incorridos em sua implantação e operação;

- a concepção a ser adotada para as intervenções físicas e operativas do projeto deverá ser aquela que maximiza a diferença B-C;

- a partir daí, e somente sobre a carteira que atenda às condições acima, deve-se hierarquizar os projetos, de acordo com seus níveis de prioridade ditados por sua relação B/C;

- cada projeto, na ordem de sua prioridade, deve equacionar sua estrutura de financiamento, sendo tal estrutura definida pela viabilidade de captação de recursos privados e/ou mobilização de recursos públicos;

- a participação da iniciativa privada, na medida em que incorpore cobrança de 
pedágio, deve submeter-se a instrumentos de controle social, de modo a garantir equilíbrio de benefícios financeiros entre investidores, financiadores, usuários (transportadores), prestadores de serviço etc.;

- a formatação dos projetos a licitar à iniciativa privada, sob o regime de concessão, deve derivar deste conjunto de condicionantes.

Considerados os aspectos descritos acima, pode-se projetar uma estrutura de processo decisório que busque cumprir um padrão eficiente de alocação de recursos no segmento de infra-estrutura rodoviária.

\section{Proposição dos limites de Aplicação para as Diferentes Metodologias}

A formulação de uma proposta de estrutura de decisão para investimentos de infra-estrutura rodoviária, em ambiente submetido à escassez de recursos, especialmente de origem pública, pode ser concebida conforme a Figura 3 apresentada a seguir; atendendo-se aos aspectos listados no item supra, faz-se uso de diferentes metodologias de análise de projetos, de acordo com o estágio do processo decisório e com o agente convocado à tomada de decisão.

No plano estratégico, a autoridade de política econômica deverá selecionar os projetos de acordo com um conjunto de premissas qualitativas e quantitativas que se configuram metodologicamente como avaliação por multicritérios.

Os projetos enquadrados no planejamento macroeconômico passam então a ser avaliados, de modo que se verifique sua capacidade marginal de agregar benefícios econômicos líquidos à sociedade. A concepção física e operacional dos projetos deve ser definida nesta etapa, de forma a maximizar a relação $\mathrm{B} / \mathrm{C}$ dos projetos.

Definida a concepção de máxima relação B/C, esta deverá permanecer inalterada para os estágios seguintes do processo, visto que ela é a de maior produtividade de uso dos recursos escassos, passíveis de serem mobilizados para o programa.

Projetos otimizados, que ainda assim não apresentem resultado positivo na diferença B-C, deverão ser descartados, de acordo com a presente proposição; portanto, no nível de decisão de caráter econômico, a metodologia B-C mostrase soberana, devendo ser o instrumento primordial dos órgãos de coordenação do programa (os poderes regulador e concedente). 


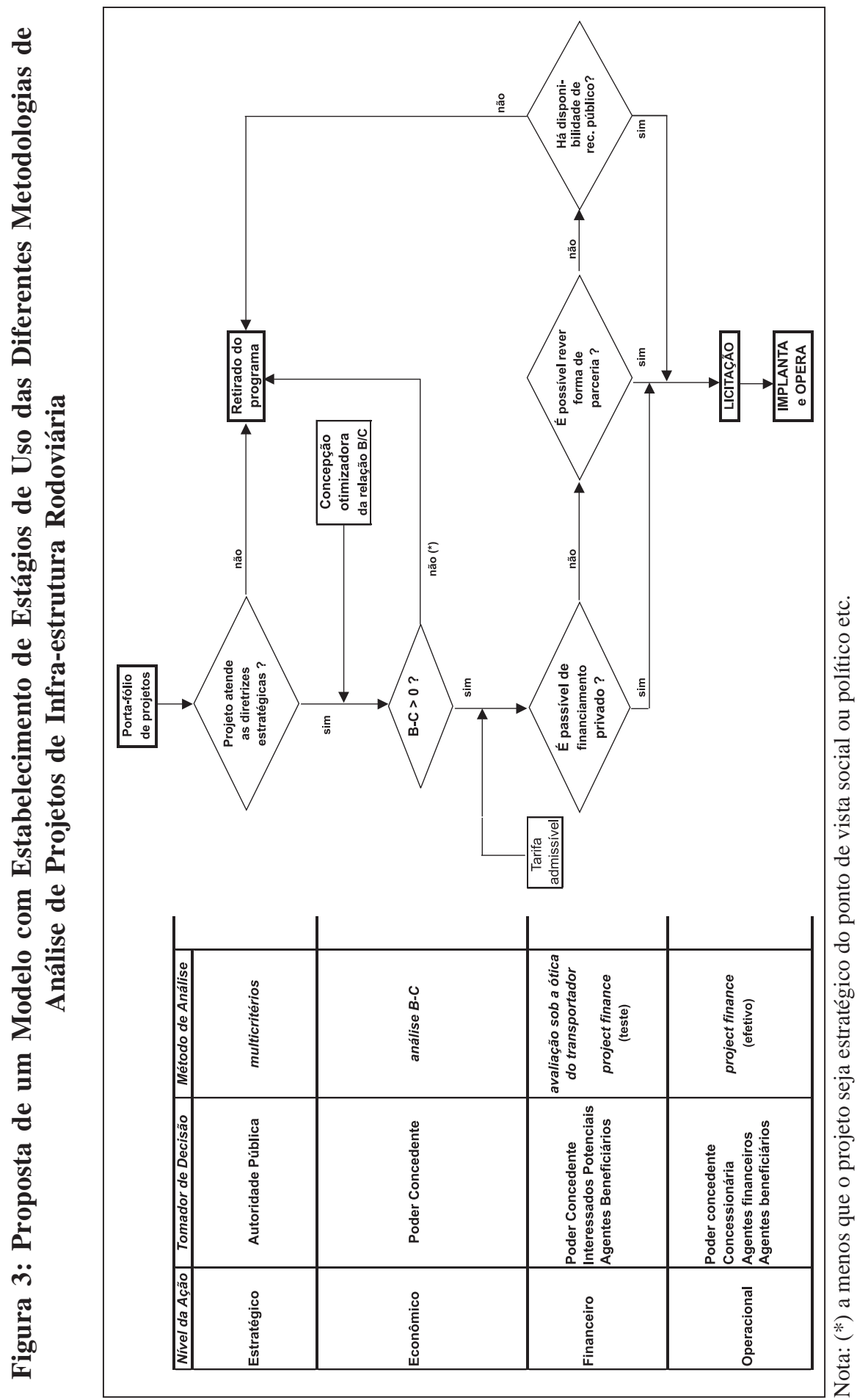


Para o conjunto de projetos que avançam para a etapa seguinte, ou seja, para aqueles com a diferença B-C positiva, só resta definir, então, a fonte de recursos capaz de financiá-los.

Assim, precedido de uma análise do nível tarifário admissível para a prática de pedagiamento, com uso de uma avaliação financeira sob a ótica do transportador, deve-se proceder a testes de viabilidade/financiabilidade, à luz do método project financing, com dados de projeção a serem obtidos junto aos agentes interessados.

Projetos não viáveis, do ponto de vista de sua financiabilidade com recursos privados, não devem a priori ser descartados ou terem alterada sua concepção, cuja eficiência está garantida pela maximização de sua relação B/C. A primeira tentativa alternativa a uma modelagem de financiamento integral com recursos privados deve ser a de parceria com o setor público.

Caso este também não se mostre um caminho viável ou adequado, deve-se recorrer ao uso exclusivo de recursos públicos para o financiamento do projeto, uma vez que, vale lembrar, o projeto apresenta B-C > 0 e B/C máximo.

Como os projetos vêm da etapa de análise econômica já priorizados e como os recursos públicos são limitados, a partir de certo ponto da hierarquização dos projetos, alguns, ao não obterem nível mínimo de financiabilidade, acabarão sendo descartados ou postergados, a menos, naturalmente, de decisões de caráter estratégico, político ou social.

Na etapa de análise financeira, por certo irão envolver-se, além dos agentes promotores do programa, todo o conjunto de agentes interessados na conquista de contratados de concessão. O instrumental de análise de todos, nesta fase, basear-se-á no project financing ou, eventualmente, para os transportadores, o método de análise deve ser o de avaliação financeira sob sua ótica de despesas e economias.

A presente proposta, dessa forma, procura demonstrar a factibilidade de um processo que, preservando a preocupação primeira de gerar benefícios econômicos líqüidos com a implementação de projetos no segmento de infra-estrutura rodoviária, assegura a continuidade da eficácia de um programa de atração de capitais privados, na medida em que possibilita uma oferta ampliada de projetos ao setor privado, com ou sem parceria de recursos públicos. Esta proposta diferencia-se do modelo hoje praticado em diversos pontos, sendo possível destacar os seguintes:

- subordina todo o programa a um plano estratégico, diferentemente de formulálo a partir de necessidade física ou por conta de experiências internacionais; 
. não parte da impossibilidade de mobilização de recursos públicos para deflagrar o programa e, sim, da oportunidade de implementação de projetos com geração de benefícios líqüidos para a economia;

- prioriza os projetos com maior produtividade econômica (maior B/C), ao invés de buscar construir projetos simplesmente financiáveis;

- mantém o compromisso com a eficácia do programa (sua factibilidade via atração da iniciativa privada), sem deixar de privilegiar a eficiência na seleção de projetos (aqueles com maior relação B/C); e

- propõe o uso de cada metodologia de análise de projeto no estágio decisório em que ela se mostra útil, eficiente e compatível com os objetivos que cada agente decisor deve perseguir.

\section{Conclusão}

No Brasil, os programas governamentais de concessão de rodovia, premidos pela necessidade de dar agilidade aos investimentos na recuperação da malha rodoviária, deteriorada por anos de não-investimento por conta da escassez de recursos públicos, têm privilegiado a factibilidade de atração de capitais privados na concepção dos projetos, aí incluídos o programa de investimentos a realizar, o padrão operacional, o nível tarifário etc. Neste sentido têm sido pautados os processos decisórios da administração pública na gestão de tais programas.

Tal postura, por definição, conduz à utilização, como instrumento de decisão, do modelo project financing para conceber e selecionar os projetos a licitar junto à iniciativa privada, empregando-o em todos os níveis de decisão, praticamente tendo sido descartado o uso das demais metodologias, com isso perdendo-se o foco sobre aquilo que seu uso proporciona como instrumento de decisão.

O método project financing, assim como o método B-C e os demais critérios de análise de projetos, geram indicadores para tomada de decisão de investimentos; antes de serem métodos concorrentes, são métodos complementares, com cada um servindo a um determinado propósito, construindo determinado resultado, prestando-se à decisão de determinado agente.

Respeitando o sentido de não comprometer a agilidade do programa, é proposto, neste trabalho, um processo decisório em que apenas projetos com máxima geração de benefícios por unidade de custo venham a ser implementados e, deste 
conjunto, apenas aqueles atrativos à iniciativa privada submetam-se a esta modelagem de financiamento.

Dentro do modelo de decisão proposto, cada metodologia seria aplicada no nível de decisão adequado aos indicadores que ela gera, proporcionando como resultado final a implementação de projetos ótimos sob todos os aspectos de análise.

Evidentemente a proposta aqui apresentada apenas delineia o processo a ser implementado, reconhecendo que tantos são os agentes envolvidos, que sua implementação não pode basear-se em um fluxo de decisões e ações no padrão simplificado que ora se formulou.

O que se buscou, entretanto, foi caracterizar a possibilidade de se obter a participação privada nos investimentos em infra-estrutura rodoviária, sem perder de vista e de propósito os benefícios econômicos e sociais que se podem cumprir com as realizações rodoviárias.

A subordinação da concepção dos projetos à sua financiabilidade, pelo contrário, apesar de no curto prazo ser eficaz como instrumento de atração de investidores e financiadores, pode e deve, a médio e longo prazo, conduzir o programa a um nó institucional, no qual se confrontarão os direitos contratuais dos concessionários, o serviço da dívida junto aos financiadores e os interesses públicos da sociedade e dos usuários sobre a rodovia.

Assim, considerando que o programa de concessões rodoviárias, no Brasil, está realizado em menos de $50 \%$ do seu montante total previsto atualmente e imaginando que os novos trechos rodoviários a licitar demandem maior atenção em termos de sua viabilidade econômica (os primeiros trechos licitados foram os de maior intensidade de tráfego e maior demanda por investimento), a presente proposta de processo decisório para seleção de novos projetos ainda se mostra oportuna e susceptível de aplicação, desde logo e ao longo dos próximos anos.

O presente trabalho, certamente, não inaugura a análise de tais questões, mesmo considerando o recente ambiente de concessões rodoviárias no Brasil; porém espera ter conseguido sintetizar e ordenar um conjunto de informações e propostas, de modo a funcionar como um ponto de reflexão e início de debate para ajuste e eventual correção de rumos nos processos atualmente em curso, na análise de projetos e na alocação de recursos no segmento de infra-estrutura rodoviária. 


\section{Referências Bibliográficas}

ABCR.

Associação Brasileira de Concessionárias de Rodovias. Programa de concessão de rodovias do Estado do Paraná: anel de integração - avaliação comparativa dos benefícios dos custos operacionais dos usuários das rodovias concedidas, em relação aos custos incorridos em postos de pedágio. [S.l.: s.n], 1998. Nota técnica.

\section{ADLER, H. A.}

Avaliação econômica dos projetos de transporte: metodologia e exemplos. Rio de Janeiro: Livros Técnicos e Científicos Editora, 1978.

\section{BNDES.}

Banco Nacional de Desenvolvimento Econômico e Social. Gerência Setorial de Transporte e Logística. As concessões rodoviárias. Rio de Janeiro: BNDES, 2000.

BNDES/BIRD/DNER.

Banco Nacional de Desenvolvimento Econômico e Social/ Banco Internacional de Reconstrução e Desenvolvimento/ Departamento Nacional de Estradas de Rodagem. Manual de rodovias vicinais. Rio de Janeiro: [s.n], 1983.
BORGES, L. F. X.

Project finance e infra-estrutura: descrição e críticas. Revista do BNDES, n. 12, jun. 1998.

Convenants: instrumento de garantia em project finance. Revista do BNDES, n. 11, p.117-136, jun. 1999.

BRUTTON, M. J.

Introdução ao planejamento dos transportes. Rio de Janeiro: Interciência, 1979.

CASAROTTO FILHO, N.;

KOPITTKE, B. H.

Análise de investimentos. São Paulo: Atlas, 1998.

CHEROBIM, A. P. M. S.

Parcerias público-privadas no Brasil: os processos de privatização de segmentos de infra-estrutura de transportes, nos modos rodoviário e ferroviário e a inovação institucional. Revista de Administração Pública, v. 3, n. 2, p.169-178, mar./abr. 1999.

CLEMENTE, A. (Org.).

Projetos empresariais e públicos. São Paulo: Atlas, 1998. 
DNER.

Departamento Nacional de Estradas de Rodagem. Diretoria de Concessões Rodoviárias. Programa de concessão de rodovias federais. Brasília: [s.n.], 1998a. Nota técnica.

Editais de concorrência pública n. 592 e 595/98. Lotes 03 e 12. Brasília, $1998 b$.

Audiência pública para o programa de concessões de rodovias federais. Brasília: DNER, 1999.

FERREIRA, C. K. L.

$O$ project financing e a parceria pública-privada nos investimentos em infra-estrutura. São Paulo: Sinduscon, 1996.

OLIVEIRA, R. G. (Org.).

Avaliação do equilíbrio econômico-financeiro dos contratos de concessão de rodovias. São Paulo: FIPE/USP, 2001.

PIMENTEL NETO, C. A. Bom senso não paga pedágio. Correio Popular, Campinas, 21 nov. 2000. p. 3.

PINHEIRO, A. C.;

FUKASAKU, K. (Eds.).

A privatização no Brasil: o caso dos serviços de utilidade pública. Rio de Janeiro: OECD e BNDES, 2000.
PORTO, E.

A farra dos pedágios. Isto É Dinheiro, São Paulo, Editora Três, n. 89, 12 maio 1999.

RIGOLON, F. J. Z.;

PICCININI, M. S.

$O$ investimento em infra-estrutura e a retomada do crescimento econômico sustentado. BNDES, Rio de Janeiro, dez. 1997. Textos para discussão n. 63.

ROCHA, J. G. C.

Análise da utilização do modelo project finance como instrumento de alocação de recursos e de seleção de projetos de investimento em infra-estrutura rodoviária. Santa Bárbara do Oeste, 2001. Dissertação (Mestrado) - Universidade Metodista de Piracicaba.

ROCHA, J. G. C.;

VANALLE, R. M.

Project finance e avaliação econômica de projetos de transporte: um estudo comparativo. In: ENCONTRO DE MESTRADOS EM ENGENHARIA, 3., 1999, Santa Bárbara do Oeste. Anais... [S.l.]: UNIMEP, 1999.

\section{SÃO PAULO.}

Governo do Estado. Secretária dos Transportes. Programa estadual de desestatização e parcerias com a iniciativa privada. São Paulo, 1995. 
Programa de concessões rodoviárias. Boletim Informativo, São Paulo, jan. 1998a.

Edital de licitação n. 019/CIC/ 98 Lote 06. São Paulo, DER-SP, DERSA, 1998b.

UNITEC.

Consultores Técnicos Associados. Estudo de viabilidade eco- nômica do projeto de concessão do complexo rodoviário Estrada do Coco - Linha Verde. Rio de Janeiro, 1999.

WALD, A.;

MORAES, L. R.; WALD, A. M.

$O$ direito de parceria e a nova lei de concessões. São Paulo: Ed. Revista dos Tribunais, 1996. 